\title{
Effects of Supercooling Degree and Specimen Size on Supercooling Duration of Erythritol
}

\author{
Takahiro ADACHI, ${ }^{1)}$ Ddamulira DAUDAH ${ }^{2)}$ and Gaku TANAKA ${ }^{1) *}$ \\ 1) Department of Mechanical Engineering, Graduate School of Engineering, Chiba University, 1-33 Yayoi-cho, Inage-ku, Chiba, \\ 263-8522 Japan. $\quad$ 2) Department of Mechanical Engineering, Faculty of Engineering, Chiba University, 1-33 Yayoi-cho, \\ Inage-ku, Chiba, 263-8522 Japan.
}

(Received on April 23, 2014; accepted on August 6, 2014)

\begin{abstract}
The duration of supercooling for erythritol, a promising phase change material with a melting point of $118^{\circ} \mathrm{C}$, was investigated in a glass tube using three small specimen volumes of $0.025,0.40$, and $16.0 \mathrm{~cm}^{3}$ in glass tube diameters of $1.02,10.0$, and $27.3 \mathrm{~mm}$, respectively. The supercooling duration was measured by the temperature increase of the specimen due to the release of latent heat under a constant degree of supercooling from 38 to $98^{\circ} \mathrm{C}$. The supercooling duration was largely dependent on the supercooling degree and specimen sizes, and increased from approximately 0.1 to 20000 min with a decrease in the supercooling degree and specimen size. The effects of the supercooling degree and specimen size on the supercooling duration are discussed in terms of the Johnson-Mehl-Avrami equation and three nucleation theories based on the observed solidification position; homogeneous nucleation, heterogeneous nucleation from the wall, and heterogeneous nucleation from insoluble particles.
\end{abstract}

KEY WORDS: phase change material; thermal storage; supercooling; nucleation; latent heat; erythritol.

\section{Introduction}

Recently, more effective use of energy has become a requirement, such as the use of waste heat of less than $200^{\circ} \mathrm{C}$ from plants to heat water, homes and offices. ${ }^{1)}$ However, there are problems to realize such energy utilization, such as the time difference in supply and demand, and the distance from plants to homes and offices. Therefore, heat storage technologies should be employed to address these problems. In particular, latent heat storage that uses the phase change of a material has advantages of a larger heat storage density per unit volume and greater temperature efficiency because of the constant temperature upon phase change compared to that with sensible heat storage.

Erythritol is an artificial sweetener with a melting point less than $200^{\circ} \mathrm{C}$ that is also a phase change material expected to be employed in hot water supply applications. Erythritol has various characteristics ${ }^{2}$ that make it a suitable phase change material: a phase change temperature of approximately $120^{\circ} \mathrm{C}$ that is suitable for hot water supply, a large quantity of latent heat, low toxicity, and it can be massproduced with relatively low degradation when used repeatedly. In addition, erythritol has a problem of large supercooling. To date, Ona et al. ${ }^{3,4)}$ reported that the supercooling could be eliminated by ultrasonic irradiation effect. Horibe et al. ${ }^{5)}$ reported visualization of the melting and solidification behavior of a relatively large mass of erythritol in direct contact with heat exchangers. Thus, research on the practi-

\footnotetext{
* Corresponding author: E-mail: gtanaka@faculty.chiba-u.jp

DOI: http://dx.doi.org/10.2355/isijinternational.54.2790
}

cal use of erythritol as a phase change material has been conducted.

In addition, there has also been basic research on the supercooling of erythritol. Hirano ${ }^{6)}$ measured the degree of supercooling for erythritol masses of 0.001 to $20 \mathrm{~g}$ and revealed a monotonic increase in the supercooling degree of erythritol with a decrease in mass. Wei and Ohsasa ${ }^{7)}$ measured the supercooling degree of erythritol and estimated the parameters influencing the nucleation of erythritol by homogeneous nucleation theory.

There has also been research aimed at improving the heat exchanger performance in latent heat strage using emulsions $^{8)}$ and microcapsules ${ }^{9)}$ of the minute volume of latent heat strage materials. However, there are no such applications of erythritol and the increase in the supercooling of erythritol with a decrease in the volume (mass) is of significant interest; therefore, detailed investigation on the supercooling phenomenon of erythritol is very important.

We have studied the influence of the specimen volume and container contact area on the degree of supercooling for erythritol. ${ }^{10)}$ In this study, the duration of supercooling for erythritol is measured experimentally and examined with respect to several nucleation theories.

\section{Experimental Apparatus and Method}

The experimental method employed in this study is the same as in the previous study. ${ }^{10)}$ Erythritol (Kobe Chemical Co., Ltd.) with a purity of $99.0 \%$ was used as the subject specimen. The melting point $T_{m}$, and latent heat of fusion $L$, were measured using differential scanning calorimetry 
(DSC; Shimadzu, DSC-50) to be $118^{\circ} \mathrm{C}$ and $336 \mathrm{~J} / \mathrm{g}$, respectively. Erythritol with masses $M$, in the range of $0.031-20.0 \mathrm{~g}$ was placed in glass containers with different diameters according to sample quantity. Thin glass test tubes (wall thickness $t=0.2 \mathrm{~mm}$, inside diameter $D=1.02 \mathrm{~mm}$, length $=$ $30 \mathrm{~mm})$ and large test tubes $(t=1.2 \mathrm{~mm}, D=10.0$ and $27.3 \mathrm{~mm}$, length $=60$ and $70 \mathrm{~mm}$ ) were used. The material composition of both the thin and large test tubes is relatively close to borosilicate glass. The mean surface roughness of the thin and large test tubes measured with a surface roughness measuring apparatus (Mitutoyo, SV 700 3D) were respectively 0.0077 and $0.0069 \mu \mathrm{m}$; therefore, there was no significant difference between the two values.

Table 1 shows specimen volume $V$ of the liquid phase $\left(130^{\circ} \mathrm{C}\right)$, the inner diameter of the container $D$, the mass of contained specimen $M$, and the container contact area $S$, which were used for the three experimental conditions of $V=0.025,0.40$, and $16.0 \mathrm{~cm}^{3}$.

For the thin test tube with $D=1.02 \mathrm{~mm}$, the glass tube was first attached to a micropipette (minimum scale: $0.2 \mathrm{~mm}^{3}$ ) to insert a $25.0 \mathrm{~mm}^{2}$ melted specimen of erythritol. Afterwards, a $0.1 \mathrm{~mm}$ thick piece of glass was attached to the base of the glass tube using a heat-resistant adhesive material. The mass calculated from the density of the liquid $\left(1.25 \mathrm{~g} / \mathrm{cm}^{3}\left(130^{\circ} \mathrm{C}\right)\right)$ was $M=0.032$ g. $S$ was calculated assuming the glass test tube shape was cylindrical. For the large test tubes with $D=10.0$ and $27.3 \mathrm{~mm}$, powder specimens of $M=0.5$ and $20.0 \mathrm{~g}$ measured with an electronic balance (minimum scale: $0.01 \mathrm{~g}$ ) were placed in the test tubes, which were then heated to melt the specimens. The volumes were calculated using the density to be $V=0.4$ and $16.0 \mathrm{~cm}^{3}$. $S$ for the container was calculated as a combination of the column and the base hemisphere.

When in use, each container with a specimen was enclosed at the top using a thin layer of silicone oil (specific gravity: 0.96 , quantity of enclosure: $0.04-5 \mathrm{~cm}^{3}$ ) to avoid entry of foreign materials from the surroundings that could affect the supercooling of the specimen. In addition, a Ktype thermocouple $(0.1 \mathrm{~mm}$ diameter) was attached to the center of the outer walls of the test tubes to measure the sample temperature. To measure the experimental conditions, thermocouples were attached at positions of 1.3$24 \mathrm{~mm}$ from the bottom of the test tubes. Each thermocouple was calibrated using a mercury thermometer with a reading accuracy $\pm 0.1^{\circ} \mathrm{C}$, and the temperature measurement accuracy was determined to be $\pm 0.2^{\circ} \mathrm{C}$.

Test tubes filled with the sample and silicone oil were inserted into holes drilled in an aluminum block and subjected to cooling. Figure 1 shows a schematic diagram of the experimental apparatus, which consists of an aluminum block $\left(110 \times 110 \times 70 \mathrm{~mm}^{3}\right)$ to hold and heat the test tubes uniformly, an aluminum hot plate $\left(200 \times 200 \times 20 \mathrm{~mm}^{3}\right)$ with its temperature controlled by cooling water circulation and a

Table 1. Specimen size conditions.

\begin{tabular}{ccccc}
\hline & $V\left[\mathrm{~cm}^{3}\right]$ & $D[\mathrm{~mm}]$ & $M[\mathrm{~g}]$ & $S\left[\mathrm{~cm}^{2}\right]$ \\
\hline (i) & 0.025 & 1.02 & 0.031 & 0.97 \\
(ii) & 0.40 & 10.0 & 0.50 & 2.1 \\
(iii) & 16.0 & 27.3 & 20.0 & 27.3 \\
\hline
\end{tabular}

heater, a constant low temperature bath, an electrical power source and a programmable PID controller (Chino, JP1131000 ). The aluminum block is placed on the aluminum hot plate and can hold up to 4 to 16 test tubes simultaneously, according to test tube diameters. In this experiment, the test tubes protrude from 2 to $10 \mathrm{~mm}$ from the aluminum block; therefore the samples are not filled up past the protruding part of the test tube. Temperatures measured with the K-type thermocouples attached to the test tube are uploaded to the PC via a data logger (Toyo Technica Personal Daq/56). In addition, a separate data logger (Graphtec, GL500 Midi Logger Dual) was employed to acquire 16 data from one experiment with the glass narrow tubes. During the experiments, glass wool was used to insulate the test tubes containing the sample, hot plate and aluminum block.

Figure 2 shows an experimental temperature-time program. At first, a sample enclosed within a container is melted by the hot plate and then maintained at a constant temperature of more than $130^{\circ} \mathrm{C}$. The test tube with the sample is then placed in an aluminum block for $10 \mathrm{~min}$ and later cooled to a desired temperature at a cooling rate of $0.5^{\circ} \mathrm{C} / \mathrm{min}$. Afterwards, the specimen temperature is again maintained at a constant temperature, which is expressed as the supercooling degree $\Delta T$ in this experiment. $\Delta T$ is defined as the difference between the melting point $T_{m}$, and the specimen temperature, $T$ :

$$
\Delta T=T_{m}-T
$$

$\Delta T$ was varied from 38 to $98^{\circ} \mathrm{C}$ during the experiment and the specimen temperature was recorded at $1 \mathrm{~s}$ intervals.

When solidification of the specimen occurs during an experiment, a data logger records the temperature peak from the sample due to the release of latent heat. The experiment is stopped when all the samples are solidified. Figure 3 shows a typical example of the sample temperature. The experimental data was arranged as shown in Eq. (2), where the supercooling duration $\Delta t$ is defined as the difference between the time at the isothermal starting temperature $t_{s}$, and that at the peak temperature, $t_{e}$.

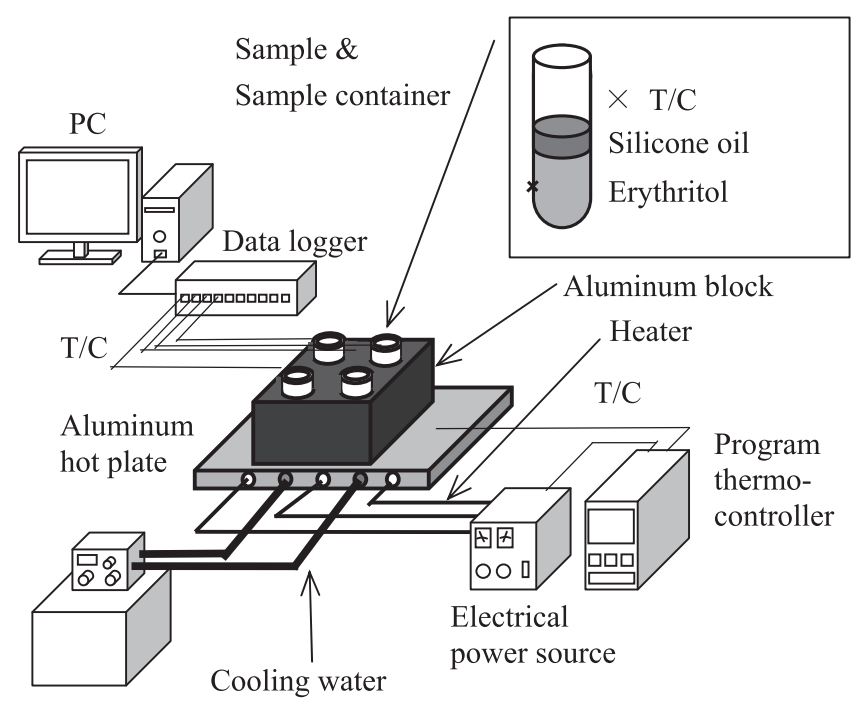

Constant low temperature bath

Fig. 1. Experimental apparatus. 


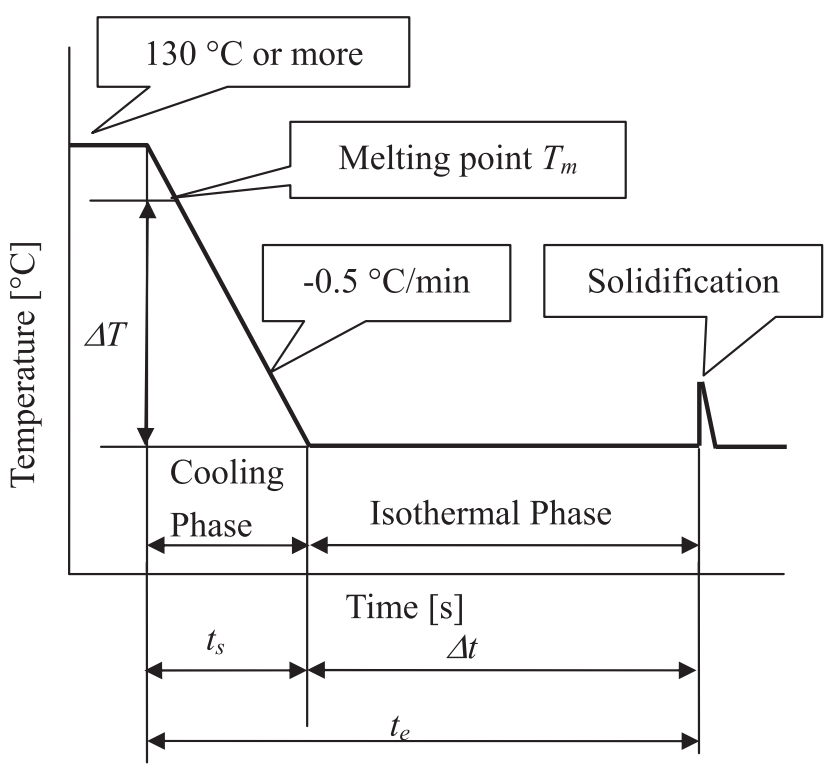

Fig. 2. Experimental temperature-time program.

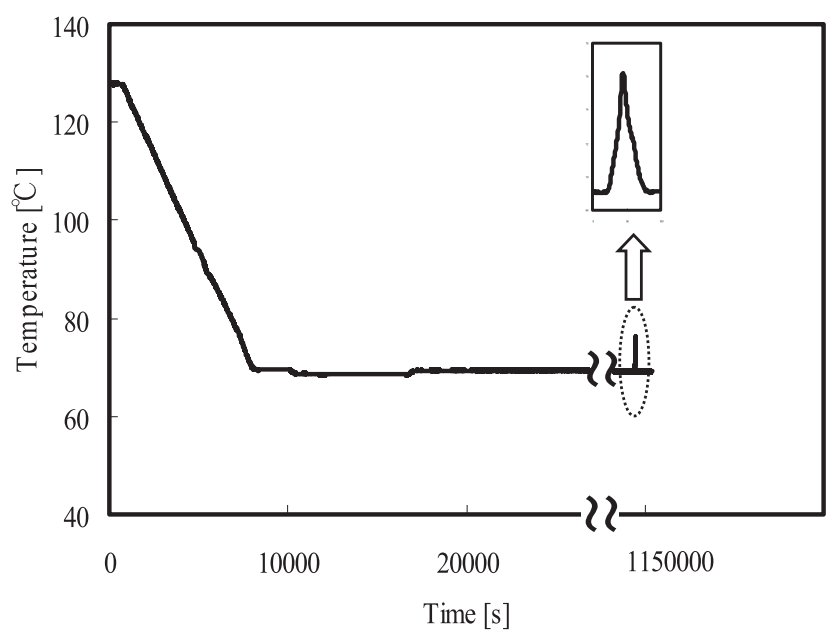

Fig. 3. Typical temperature-time curve measured at $\Delta T=48^{\circ} \mathrm{C}$ and $V=0.025 \mathrm{~cm}^{3}$

$$
\Delta t=t_{e}-t_{s}
$$

All the measurements reported were for one cooling rate of $0.5^{\circ} \mathrm{C} / \mathrm{min}$, although the cooling rate was changed to 0.25 and $1^{\circ} \mathrm{C} / \mathrm{min}$ to examine the effect on $\Delta t$ under the condition of $V=0.40 \mathrm{~cm}^{3}$ and $\Delta T=63^{\circ} \mathrm{C}$. From this result, the difference in the mean of $\Delta t$ was only $11 \mathrm{~min}$ and very small compared to the range of dispersion of experimental results. Furthermore, the spatial distribution of the sample temperature was measured under the following experimental conditions: a cooling rate of $0.5^{\circ} \mathrm{C} / \mathrm{min}, V=16.0 \mathrm{~cm}^{3}$ and $\Delta T=$ $18^{\circ} \mathrm{C}$. At the start of the isothermal temperature condition, a temperature difference of ca. $2^{\circ} \mathrm{C}$ was observed in the container height direction, and that of ca. $1^{\circ} \mathrm{C}$ was observed in the circumferential direction. Just before solidification, temperature differences of ca. 1 and $1.5^{\circ} \mathrm{C}$ were observed in the container height and circumferential directions, respectively.

As a preliminary experiment, the position where solidification occurred under each condition was photographed using a video camera (Sony, TRV-900) and a flexible scope (3R, WFX-S03).

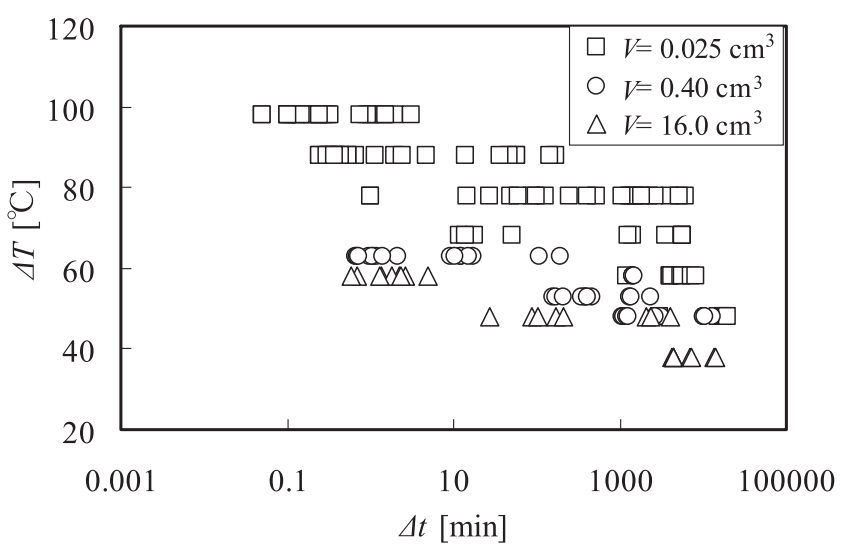

Fig. 4. Relationship between the degree of supercooling and the supercooling duration.

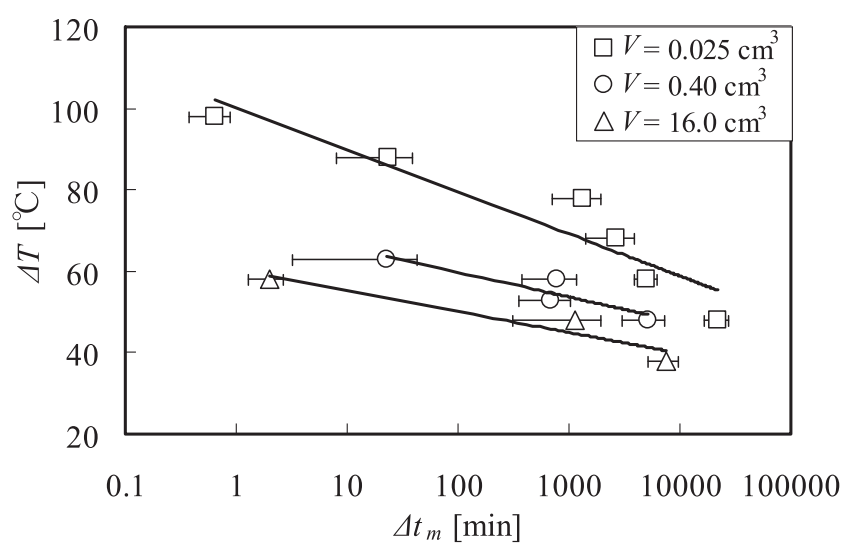

Fig. 5. Relationship between the average degree of supercooling and the supercooling duration.

\section{Results}

\subsection{Effect of $\Delta T$ on $\Delta t$}

Figure 4 shows measurements of $\Delta t$ under each condition. In Fig. 4 , the number of plots is 8 to 24 for each condition. The plot range shows significant variation of $\Delta t$ with $\Delta T$. For $V=0.025 \mathrm{~cm}^{3}$ and $\Delta T=98^{\circ} \mathrm{C}, \Delta t$ ranges from 0.1 to $3 \mathrm{~min}$, whereas for $\Delta T=48^{\circ} \mathrm{C}$, the range varied from 3000 to $20000 \mathrm{~min}$. It is therefore considered that there is a tendency for $\Delta t$ to decrease with an increase in $\Delta T$.

\subsection{Effect of $V$ on $\Delta t$}

Figure 5 shows the mean value $\Delta t_{m}$, for each experimental result of $\Delta T$ plotted in Fig. 4, where the horizontal error bars represent $90 \%$ confidence intervals for the population mean. Solid lines show approximated fit for $\Delta t_{m}$ of each specimen size. Under experimental conditions for the same $\Delta T, \Delta t$ varied according to the condition of the sample; $\Delta t$ became smaller in the order of $V=0.025,0.40$, and $16.0 \mathrm{~cm}^{3}$.

\subsection{Observation of Solidification Position}

The typical appearance and position of solidification for the $V=0.025,0.40$, and $16.0 \mathrm{~cm}^{3}$ samples at $\Delta T=88,58$, and $48^{\circ} \mathrm{C}$, respectively, are shown in Figs. 6 and 7. Figure 7 shows that solidification mainly starts from all over the $V=16.0 \mathrm{~cm}^{3}$ sample. In contrast, solidification occurs from 


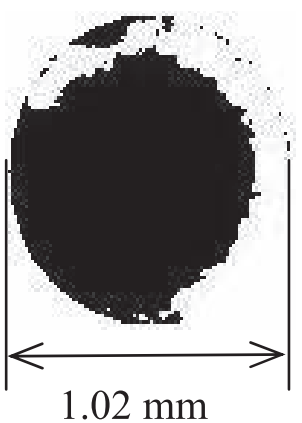

(a) $V=0.025 \mathrm{~cm}^{3}$

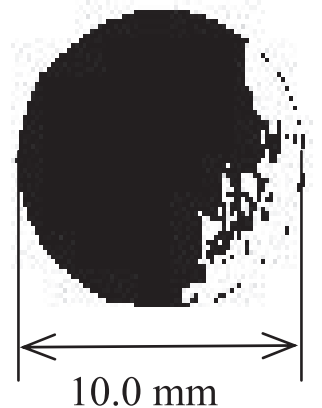

(b) $V=0.40 \mathrm{~cm}^{3}$

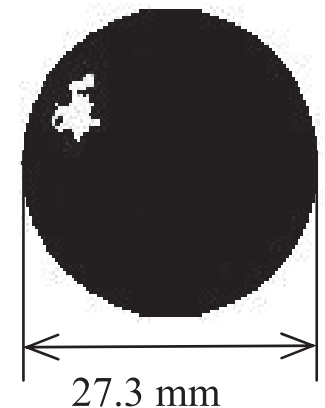

(c) $V=16.0 \mathrm{~cm}^{3}$

Fig. 6. Typical appearance of solidification for the three specimen conditions.

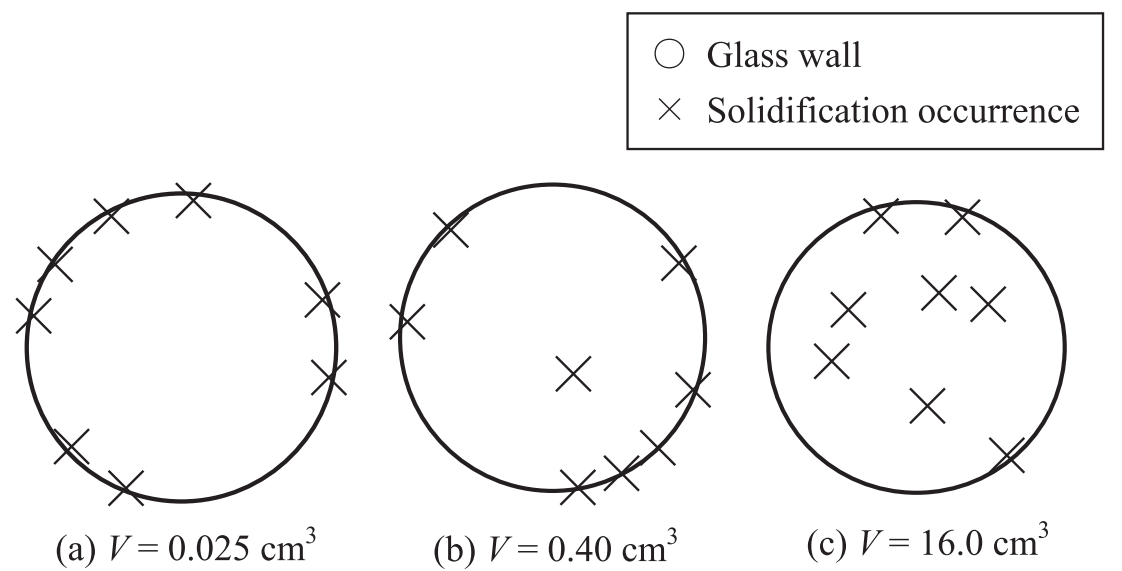

Fig. 7. Positions of solidification for the three specimen conditions.

the surface of the container wall in the $V=0.025$ and $0.40 \mathrm{~cm}^{3}$ samples. This is because the factor that causes solidification changes from insoluble particles to the container surface as $V$ becomes small.

\section{Discussion}

The relationship between the supercooling degree and duration presented in section 3.1 was considered using the Johnson-Mehl-Avrami (JMA) equation ${ }^{11)}$ shown in Eq. (3), which is commonly used for the transformation rate $X$ of an alloy. To calculate time $t, X$ in Eq. (4) is assumed to be 0.5 , but $t$ is altered by only the forth root of the volume fraction which crystallizes in time $t{ }^{12)}$ the effect of $X$ is considered to be small.

$$
\begin{gathered}
X=1-\exp \left(-\frac{\pi}{3} J G^{3} t^{4}\right) \\
t=\sqrt[4]{\frac{3 \ln (1-X)}{\pi J G^{3}}} \ldots \ldots . .
\end{gathered}
$$

$J$ is the nucleation rate and $G$ is the crystal growth rate.

Based on the observed solidification positions given in section 3.3, $J$ and $G$ were estimated according to three different nucleation theories; homogeneous nucleation, heterogeneous nucleation from a wall surface, and heterogeneous nucleation from an insoluble particle. The detailed nucleation theories and estimation methodologies are described in the Appendix.

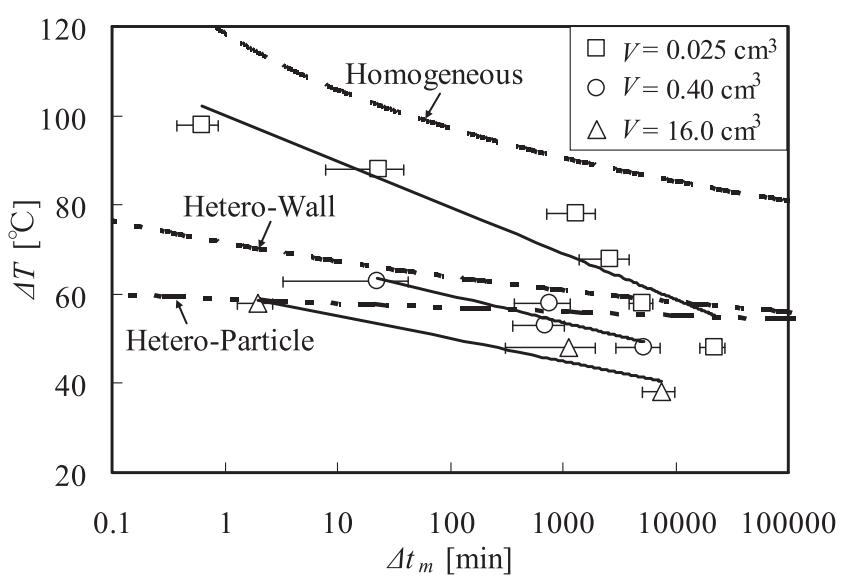

Fig. 8. Comparison of experimental and theoretical results.

The mean experimental values and those estimated according to the three nucleation theories are shown in Fig. 8. The plots show the average experimental values and the solid lines show the approximate curves for each average. The dashed lines show the values calculated assuming homogeneous nucleation, heterogeneous nucleation from a wall surface, and heterogeneous nucleation from insoluble particles. The tendency of $\Delta t$ to increase with a decrease in $\Delta T$ appears for all estimates, and there is a similar tendency between the estimated and experimental values. The reason for the increase in $\Delta t$ with the decrease in $\Delta T$ is that $J$ and $G$ are present in the denominator of Eq. (4) and decrease 
with a decrease in $\Delta T$.

For the same $\Delta T$, the estimation value of $\Delta t$ by homogenous nucleation is large and then becomes small in the order of heterogeneous nucleation from a wall surface $>$ heterogeneous nucleation from insoluble particles. This tendency and the solidification positions given in section 3.3 indicate that the change in $\Delta t$ by $V$ is due to the presence or absence of insoluble particles, which influence a change in the nucleation factor from impurities to the container wall surface, as evidenced from $V=16.0$ to $0.40 \mathrm{~cm}^{3}$. The factors that influence the change in the mode of nucleation include the number of insoluble particles $n_{p}$, and $S$, which change with a decrease in $V$. It is considered, from a former study, ${ }^{10)}$ that $n_{p}$ is approximately 1000 per unit volume. The size of insoluble particles vary in diameter with a range of $0.1-100 \mu \mathrm{m}$. Paticles with average size of $1 \mu \mathrm{m}$ order in diameter are considered to be yeast resdues from Erythritol manufacturing process where as particles of diameter more than $1 \mu \mathrm{m}$ order are considered to be dust or impurities from the surrounding. Yeast particles are oval shaped where as dust and other impurities from the surrounding are considered to be corner stone-like paticles in shape. $n_{p}$ decreases monotonically with a decrease in the specimen size when insoluble particles are assumed to be homogeneously distributed. An extreme decrease in the number of insoluble particles results in a decrease in the probability of solidification from insoluble particles in the specimen, while the probability for solidification from the container wall surface increases.

$\Delta t$ for $V=0.025 \mathrm{~cm}^{3}$ has a median estimated value, which indicates heterogeneous nucleation from the wall surface and homogeneous nucleation. It is assumed that heterogeneous nucleation from a wall surface is dominant because the position of solidification was the container wall surface in the experiment with $V=0.025 \mathrm{~cm}^{3}$. However, the experimental value is greater than the estimated value. In the study reported by Hori, ${ }^{13}$ ) the increase in the degree of supercooling by supercooled water being trapped in a narrow gap could also be applied to erythritol. The narrow gap reported by Hori was $10 \mu \mathrm{m}$, which is smaller than that in the present study. The reason for the increase in the supercooling duration for erythritol in a larger column than that for water is due to the restriction of molecular movement, i.e., the viscosity of erythritol is approximately 4 times that of water and the molecular weight of erythritol is approximately 7 times larger than that of water.

\section{Conclusion}

The supercooling duration $\Delta t$ for erythritol was experimentally measured under conditions of $V=0.025-16.0 \mathrm{~cm}^{3}$ and $\Delta T=38-98^{\circ} \mathrm{C}$. The following conclusions were obtained based on the observed solidification positions with consideration of the JMA equation and classic nucleation theories.

(1) $\Delta t$ changed from 0.1 to $20000 \mathrm{~min}$ and was strongly influenced by $\Delta T$ because $J$ and $G$ decrease with a decrease in $\Delta T$.

(2) $\Delta t$ increases with a decrease in specimen size, which can be explained by a change in the nucleation behavior and position of solidification due to the change in specimen size.

\section{REFERENCES}

1) F. Sato: "Honebuto-no" Energy Roadmap, Kagaku Kogyo-sha, Kanagawa, (2005), 335.

2) H. Kakiuchi, M. Yamazaki, S. Chihara, Y. Terunuma, Y. Sakata and T. Usami: IEA Annex 10-PCMs and Chemical Reactions for Thermal Energy Storage, 2nd Workshop, IEA, Paris, (1998).

3) E. P. Ona, X. Zhang, K. Kyaw, F. Watanabe, H. Matsuda, H. Kakiuchi, M. Yabe and S. Chihara: J. Chem. Eng. Jpn., 34 (2001), 376.

4) E. P. Ona, X. Zhang, S. Ozawa, H. Matsuda, H. Kakiuchi, M. Yabe, M. Yamazaki and M. Sato: J. Chem. Eng. Jpn., 35 (2002), 290.

5) A. Horibe, H. Inaba, N. Haruki, Y. Higashi, K. Takahashi, P. Tu and T. Mizusawa: Proc. 44th Jpn. Heat Transf. Symp. I, HTSJ, Tokyo, (2007), 281

6) S. Hirano: Proc. Ibaraki Conf., JSME, Tokyo, (2009), 245

7) L. Wei and K. Ohsasa: ISIJ Int., 50 (2010), 1265.

8) H. Inaba, S, Morita and S. Nozu: J. Jpn. Soc. Mech. Eng. (B), 59 (1993), 2882.

9) K. Yoshinori, D. Katsuragi, J. Ogawa and H. Soeda: Proc. Conf. of JSME Heat Eng. 2007, JSME, Tokyo, (2007), 117.

10) T. Adachi, T. Nakashima and G. Tanaka: J. Jpn. Soc. Refrig. Air Cond. Eng., 30 (2013), 203.

11) K. Sugimoto, K. Nagamura, T. Yamane, T. Maki, S, Kikuchi, S. Ochiai and Y. Murakami: Material histology, Asakura Publishing, Tokyo, (1991), 151.

12) F. Flanks: Biophysics and Biochemistry at Low Temperatures, Cambridge University Press, Cambridge, (1989), 56.

13) T. Hori: Low Temp. Sci. Ser. A, Phys. Sci., 15 (1956), 33.

14) N. H. Fletcher: The Chemical Physics of Ice, Cambridge University Press, Cambridge, (1970), 85.

15) R. J. Kirkpatrick: Am. Miner., 60 (1975), 798.

16) H. Inaba and K. Takeya: J. Jpn. Soc. Mech. Eng. (B), 59 (1993), 3557.

17) H. Nakae: Crystal Growth and Solidification, Agne Shofu-sya, Tokyo, (1998), 65.

\section{Appendix}

\section{Classical Nucleation Theory}

Nucleation rate $J^{14)}$ and crystal growth rate $G^{15)}$ are used in Eqs. (5) and (6):

$$
\begin{gathered}
J=\frac{n_{1} k T}{h} \exp \left(-\frac{\Delta g}{k T}\right) \exp \left(-\frac{\Delta G^{*}}{k T}\right) \\
G=\frac{f k T}{3 \pi a_{0}^{2} \eta}\left\{1-\exp \left(\frac{-\Delta G_{c}}{R T}\right)\right\} \ldots
\end{gathered}
$$

where $n_{1}$ is the number of erythritol molecules per unit volume $\left(n_{1}=6.16 \times 10^{27} \mathrm{~m}^{-3}\right), k$ is the Boltzmann constant, $T$ is the absolute temperature, $h$ is the Planck constant, $\Delta g$ is the activation energy of viscosity, and $\Delta G^{*}$ is the free energy change of a liquid molecule cluster with critical nuclear radius $r=r^{*}$. From Eq. (6), $f$ is the fraction of sites on the crystal surface available for attachment, $a_{0}$ is the thickness per molecular layer, $\eta$ is the viscosity, and $\Delta G_{c}$ is the free energy between liquid and solid. $\Delta g$ applied has a value (= $1.02 \times 10^{-20} \mathrm{~J}$ ) that was calculated from an Arrhenius plot of the viscosity measured with a distortion control-type rheometer (TA Instruments, ARES). $\eta$ was applied with a value (= $\left.5.14 \times 10^{-2} \mathrm{~Pa} \cdot \mathrm{s}\right)$ of the measured viscosity at $120^{\circ} \mathrm{C}$. $a_{0}$ is assumed to be the maximum length of an erythritol molecule (= 24.6 $\AA$ ) obtained from the molecular structural formula.

Equation (7) was used to calculate $\Delta G^{*}$, for homogeneous nucleation $\Delta G^{*}{ }_{H o m}$, while for heterogeneous nucleation, $\Delta G^{*}{ }_{\text {Het }}$ was determined using Eq. (8). Equations (9) and (10) were used to determine $f$ and $\Delta G_{c}$ :

$$
\Delta G_{H o m}^{*}=\frac{16 \pi \sigma_{c l}^{3}}{3 \Delta \mu^{2}}
$$


Supercooled liquid

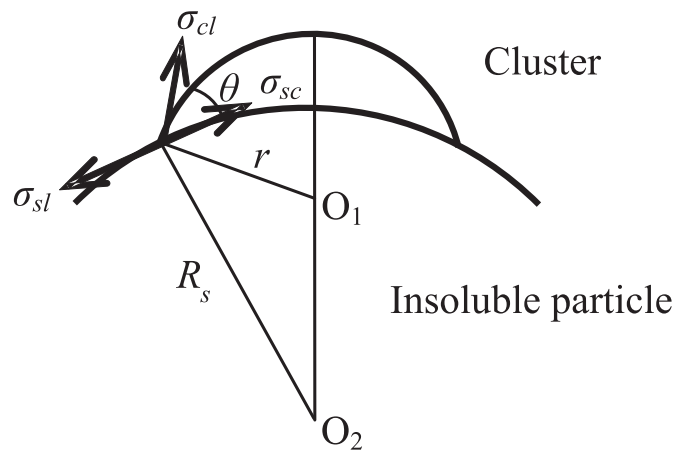

Fig. 9. Heterogeneous model based on an insoluble particle. ${ }^{16)}$

$$
\begin{array}{r}
\Delta G_{H e t}^{*}=-V_{c} \Delta \mu+\left(\sigma_{s c}-\sigma_{s l}\right) A_{s c}+\sigma_{c l} A_{c l} \\
f=\frac{\Delta T}{2 \pi T_{m}} \ldots \ldots \ldots \ldots \ldots \ldots \ldots \ldots \ldots \ldots \ldots \ldots \ldots \ldots \ldots \ldots \ldots \ldots \ldots \\
\Delta G_{c}=\frac{\Delta \mu}{\rho}
\end{array}
$$

where $\sigma_{c l}, \sigma_{s c}, \sigma_{s l}$ in Eqs. (7) and (8) indicate the interface energy for cluster-liquid, insoluble matter-cluster, and insoluble matter-liquid, respectively. $\Delta \mu$ indicates the driving force of nucleation, and $T_{m}$ and $\rho$ indicate the melting point and density $\left(T_{m}=391.16 \mathrm{~K}, \rho=1.25 \mathrm{~g} / \mathrm{cm}^{3}\right)$, respectively. For $\sigma_{c l}$, the equivalent $\left(=60.3 \mathrm{~J} / \mathrm{m}^{2}\right)$ of that given in Ref. 9) was used.

$\Delta \mu$ is calculated from Eq. (11). $L$ is latent heat per unit volume $\left(L=4.19 \times 10^{8} \mathrm{~J} / \mathrm{m}^{3}\right)$. In addition, $V_{c}, A_{s c}, A_{c l}$ from Eq. (8), in the case of heterogeneous nucleation from insoluble particles, represent geometric relations of the heterogeneity nucleation model shown in Fig. 9 and are derived from Eqs. (12) to (18). $R_{s}$ is radius of the insoluble particles, the maximum radius of insoluble particles is assumed to be $75 \mu \mathrm{m}$.

$$
\begin{aligned}
& \Delta \mu=L \frac{\Delta T}{T_{m}} \\
& V_{c}=\frac{\pi}{3} R_{s}^{3}\left[x^{3}\left\{2-3 \frac{\beta-x}{z}+\left(\frac{\beta-x}{z}\right)^{3}\right\}\right. \\
& \left.-2+3 \frac{1-\beta x}{z}-\left(\frac{1-\beta x}{z}\right)^{3}\right]
\end{aligned}
$$

\section{Supercooled liquid}

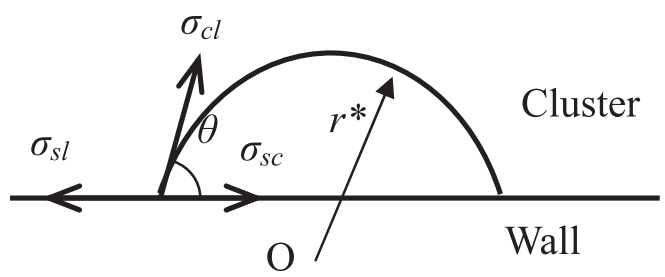

Fig. 10. Heterogeneous model based on a wall surface. ${ }^{17)}$

$$
\begin{aligned}
& A_{s c}=2 \pi R_{s}^{2}\left(1-\frac{1-\beta x}{z}\right) \\
& A_{c l}=2 \pi R_{s}^{2} x^{2}\left(1-\frac{\beta-x}{z}\right) \\
& \beta=\left(\sigma_{s l}-\sigma_{s c}\right) / \sigma_{c l} \\
& x=r * / R_{s} \\
& z=\left(x^{2}-2 \beta x+1\right)^{\frac{1}{2}} \\
& r^{*}=\frac{2 \sigma_{c l}}{\Delta \mu \rho}
\end{aligned}
$$

For heterogeneous nucleation from a container wall surface, $V_{c}, A_{s c}, A_{c l}$ derived from geometric relations of the heterogeneous nucleation model as displayed in Fig. 10 are given in Eqs. (19) to (21).

$$
\begin{gathered}
V_{c l}=\frac{\pi}{3} r^{* 3}\left(2-3 \beta+\beta^{3}\right) \\
A_{s c}=\pi r^{2}\left(1-\beta^{2}\right) \ldots \\
A_{c l}=2 \pi r^{*}(1-\beta) \ldots
\end{gathered}
$$

The value of $\beta$ used ( $=0.2)$ was the closest approximate value given in Ref. 10) for heterogeneous nucleation from insoluble particles. $\beta$ refers to $\beta=\cos \theta$ using the contact angle $\theta$ from the geometric relations shown in Fig. 10 . Therefore, $\theta$ was calculated from the width, $2 l$, and height, $h$, of a microdroplet of erythritol on a glass plate, for heterogeneous nucleation from a container wall surface. $\beta=-0.1$ was calculated from the estimated $\theta$. 